急冷されで白留は冷却途上

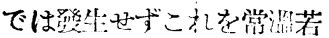

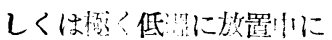

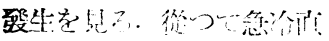

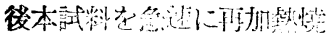

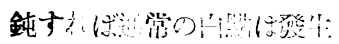

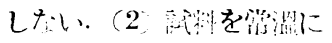

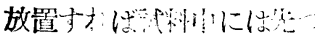

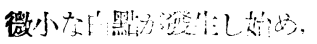
時間の約骨と其に次第に大

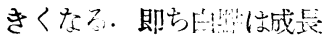

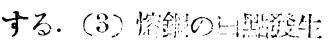

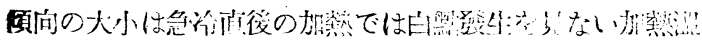

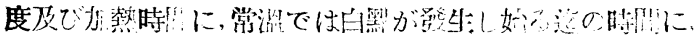

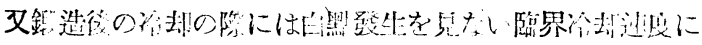

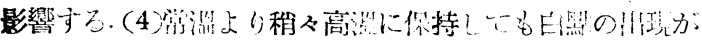

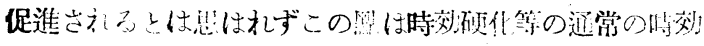

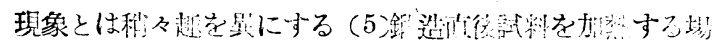

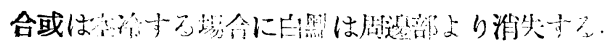

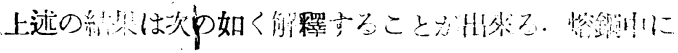

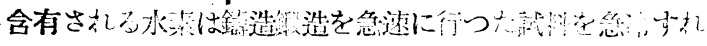

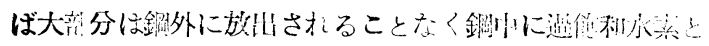

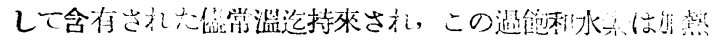

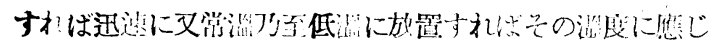

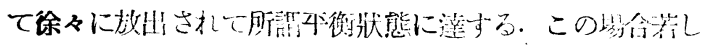

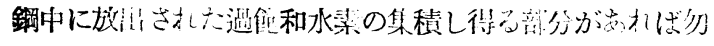

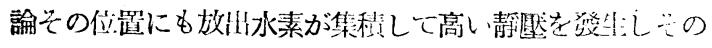

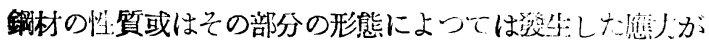

筷 2 表

\begin{tabular}{|c|c|c|c|c|}
\hline \multicolumn{4}{|c|}{ 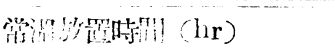 } & 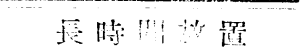 \\
\hline 10 & 15 & 20 & 30 & 时们识 \\
\hline 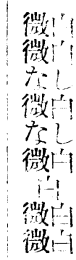 & 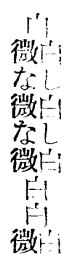 & 热 & 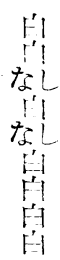 & 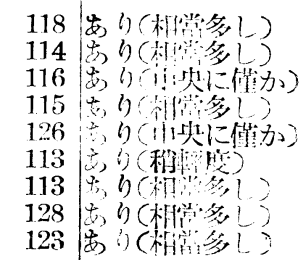 \\
\hline
\end{tabular}

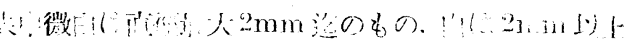

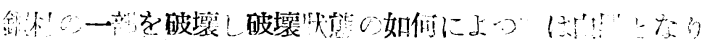

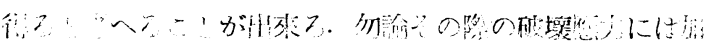

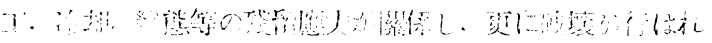

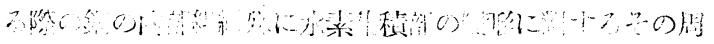

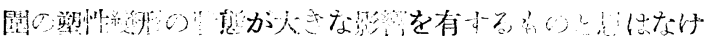

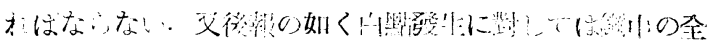

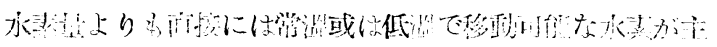

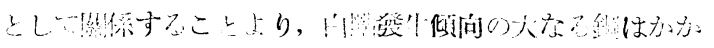

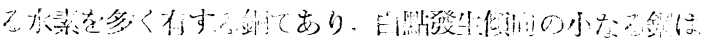

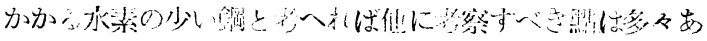

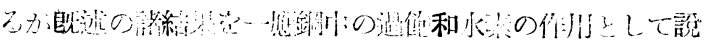
明するこょが!本る。

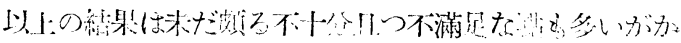

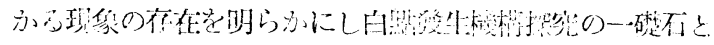

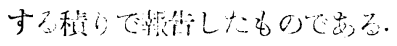

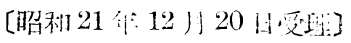

\title{
雨熱シルークロムータングステン鋼に於ける各元素の影響
}

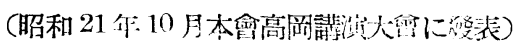

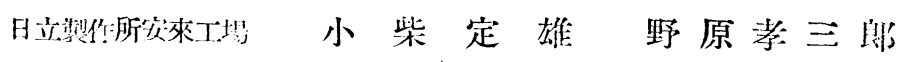

\section{I. 緒電}

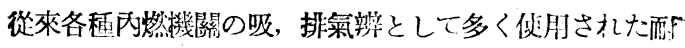
整シルークロムーモリブデン鋼は近時モリブデンの不足に

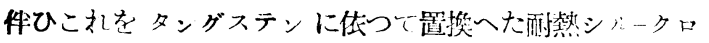

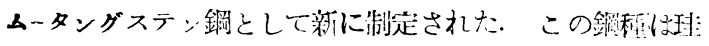
素及でク口ム等の元素を利々多量に含有するのて㷛處理长 の他賽堆取报卜において普通鋼に比し秒々罚なる吽質を 有さるのでその特性について十分知悉して就く必倠があ

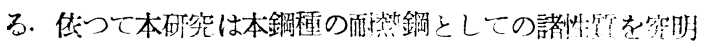

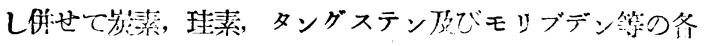

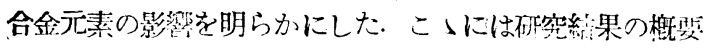
を報告する。

\section{II. 露驗試料及び零驗方法}

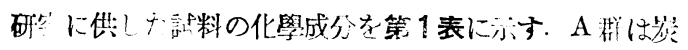

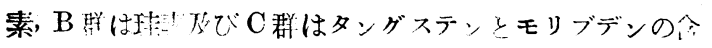

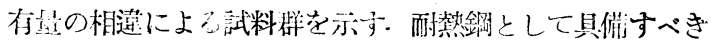
主なる諸佟件を舉げると（1）商湂度に於て相常な强度及

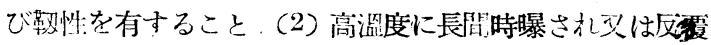

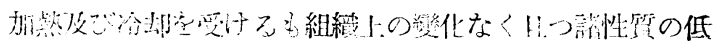

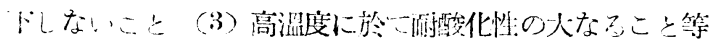
である。

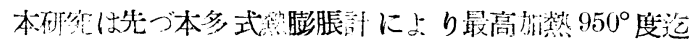

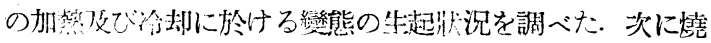

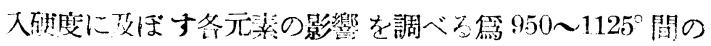

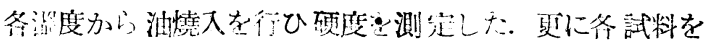

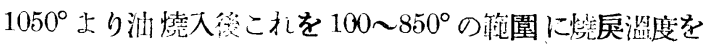

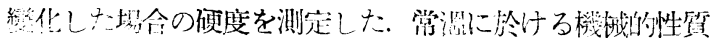

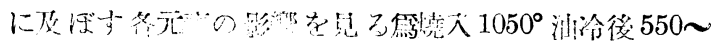

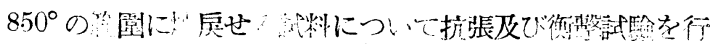

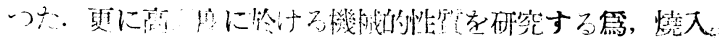




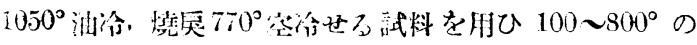

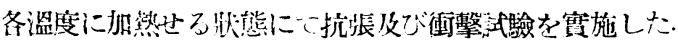

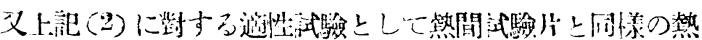

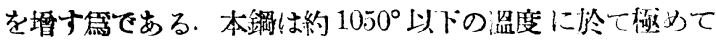
裬化性良好である。而して炭素は耐酸化性を減少与ること が和られる。

第 1 裁

\begin{tabular}{|c|c|c|c|c|c|c|c|c|c|}
\hline 化學成分 & $\mathrm{C}$ & $\mathrm{Si}$ & $\mathrm{M}[\mathrm{n}$ & $\mathrm{P}$ & $\mathrm{s}$ & $\mathrm{Mi}$ & $\mathrm{Cr}$ & IV & Mo \\
\hline 成分缷格 & $0.35 \sim 0.45$ & $1.5 \sim 2.5$ & $<0.6$ & $<0.03$ & $<0.03$ & - & $10.0 \sim 13.0$ & $0.7 \sim 1.3$ & - \\
\hline$A-1$ & 0.34 & 1.80 & 0.51 & 0.029 & 0.013 & 0.25 & 11.66 & 0.58 & 0.5 \\
\hline A -2 & 0.40 & 1.73 & 0.44 & 0.020 & 0.007 & 0.21 & 11.95 & 0.60 & 0.59 \\
\hline$A-\overline{3}$ & 0.45 & 1.72 & 0.44 & 0.025 & 0.011 & 0.15 & 11.78 & 0.57 & 0.56 \\
\hline$P-1$ & 0.3 & 1.60 & 0.4 & 0.019 & 0.010 & 0.17 & 11.78 & 0.48 & 0.30 \\
\hline $3-2$ & 0.39 & 2.09 & $0.4 \mathrm{~J}$ & 0.016 & 0.012 & 0.18 & 12.02 & 0.68 & $0.2 !$ \\
\hline$B-3$ & 0.40 & 2.45 & 0.34 & 0.015 & 0.015 & 0.11 & 11.41 & 0.77 & 0.21 \\
\hline C -1 & 0.41 & 1.81 & $0.4 ?$ & 0.017 & 0.011 & 0.18 & 11.53 & 0.84 & 0.43 \\
\hline$C-2$ & 0.41 & 1.88 & 0.44 & 0.003 & 0.010 & 0.15 & 11.22 & 1.19 & \\
\hline
\end{tabular}

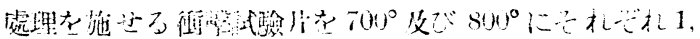

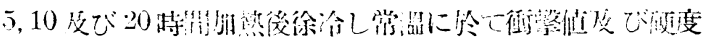

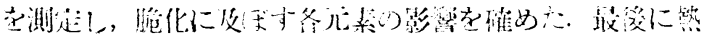

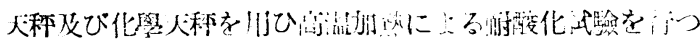

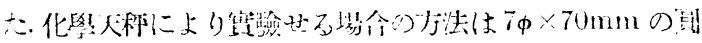

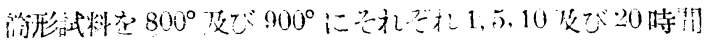

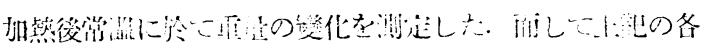

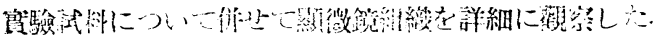

\section{III. 䨘 驗 結 果}

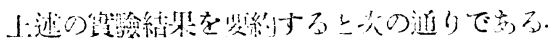

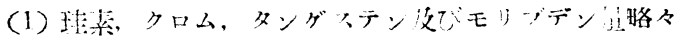

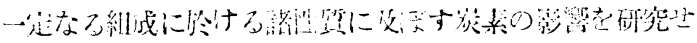

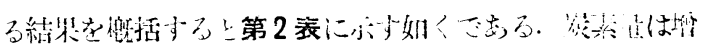

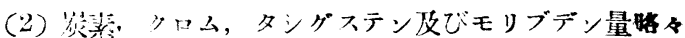

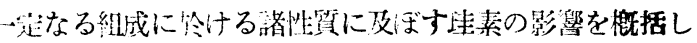

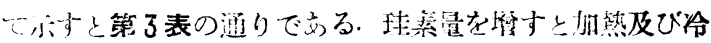

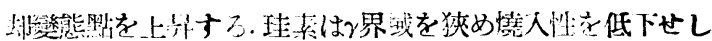

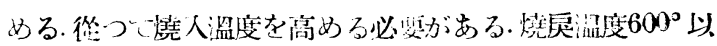

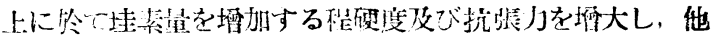

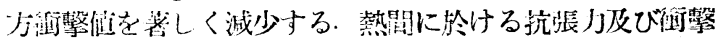

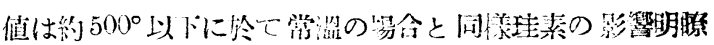

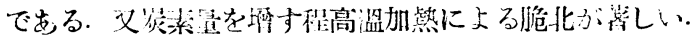

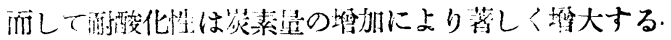

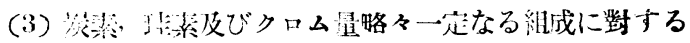
タングステン波びモリブデン含有㻎の相違に上る影響を概

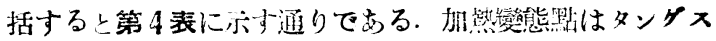

第 2 表

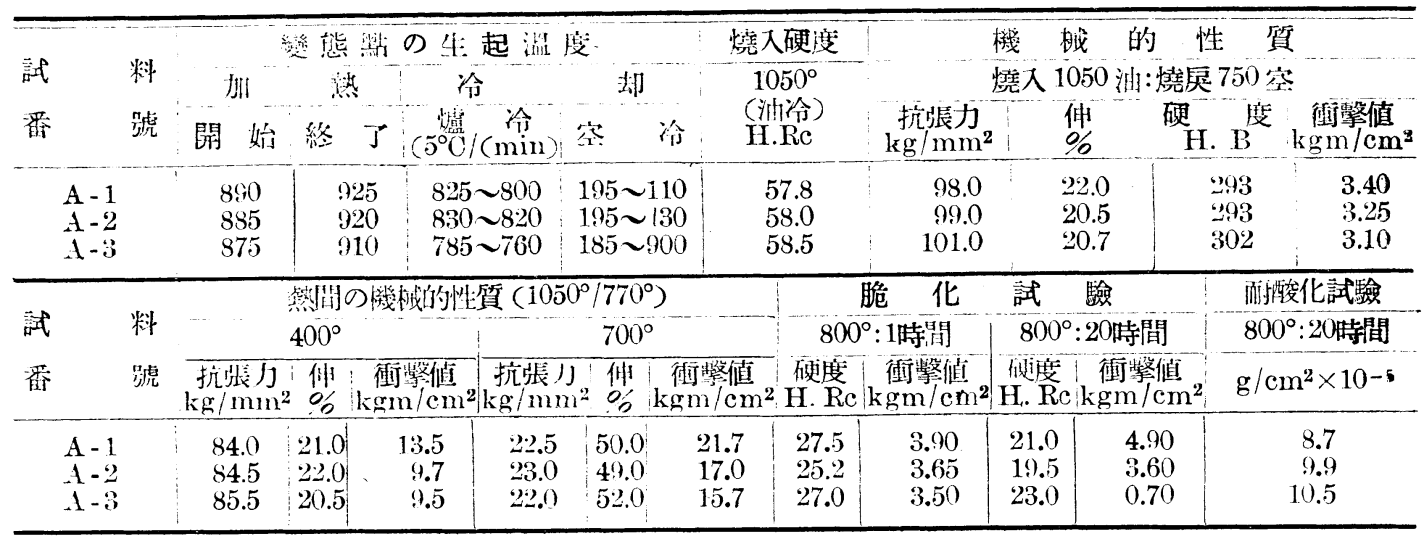

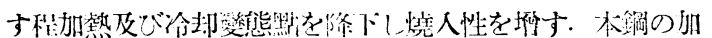

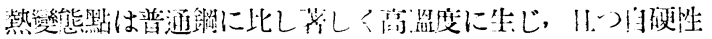

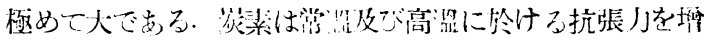

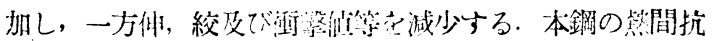

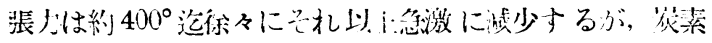

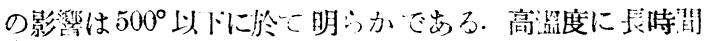

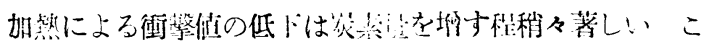

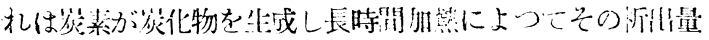

テンの含有量多いC-2 の方稍々高温度に生制するが：の

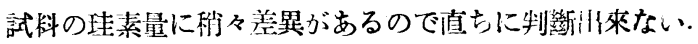
而して兩者の䓡處理による硬度の變化並に機战的性質等は 徐り大差なく、唯モりブデン量多い方が僅かに䩒性が大で H.つ㜀酸化性す稍々是好である.

$$
\text { IV. 結 }
$$

上述の研究結啉を綜合して從來の耐熱シルークロ:ーモり ブデン鋼のモリブデンを等最のタングステンに依つて策 
第 3 装

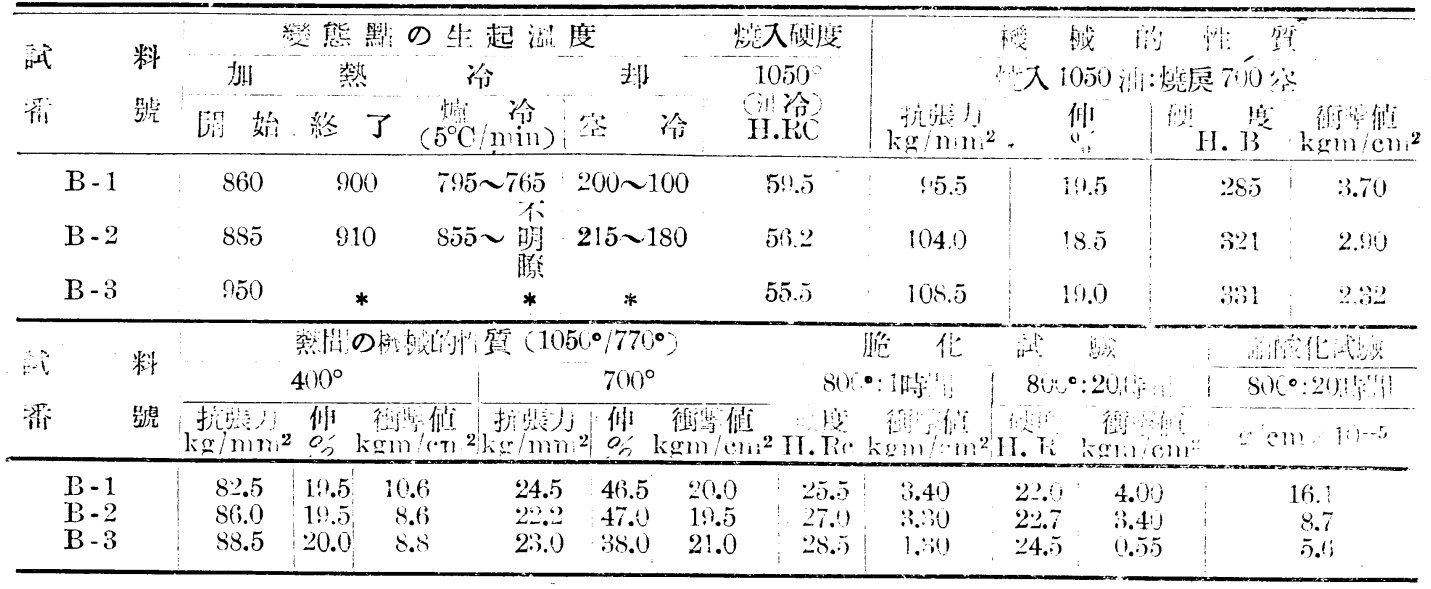

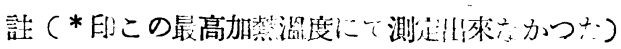

第 4 悲

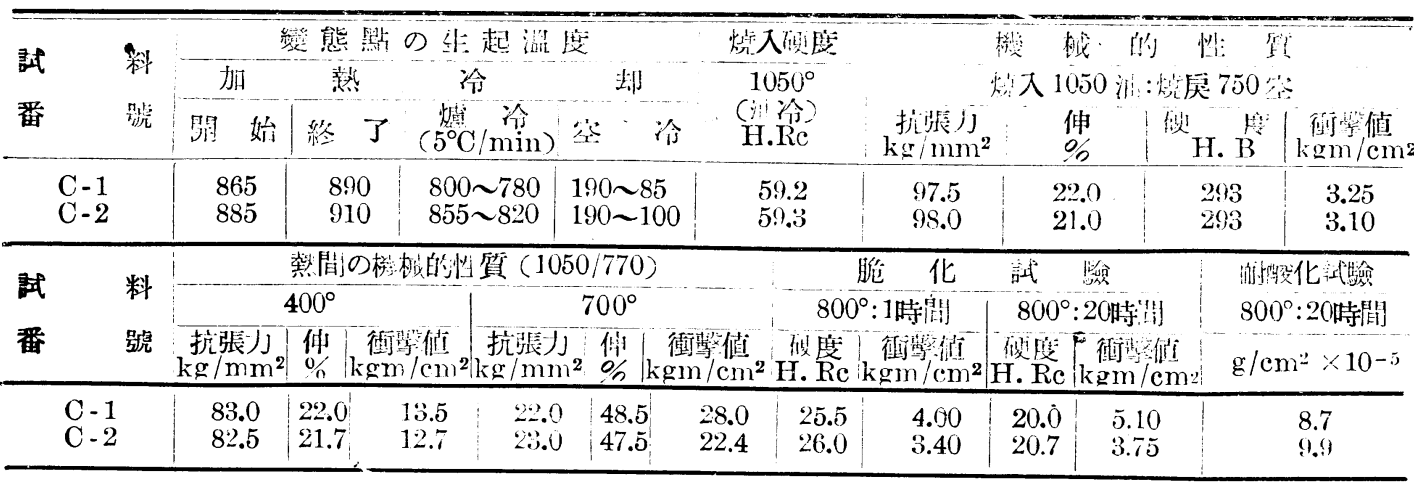

换した耐熱シルークロムータングステン鋼は轨素及び炎素等

の元素を適當に添加することに伡つて實用上们等の萔毛も

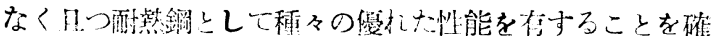
認した。

\section{鋼鑄物砂の燒着に關する一考察}

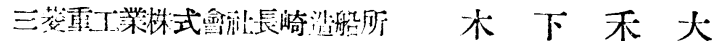

\section{I. 緒 辰}

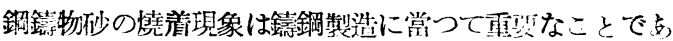
りながら從來放任された形になつて居たのでこれを檢討

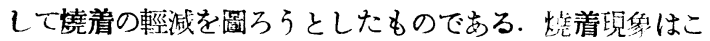
札大別して

（1）鑄物の表面と鋞物砂との接觸部に起るもの（2）鏑

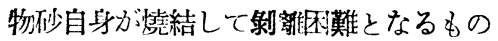

の二つとすることが出來る. 第一の\&のは節物表而に忛來 た脏化鐵が仯と接觸して愹融したものでまり，第二の州の は繶物砂自身が不純なため融烈の低いこをにするものと考 ヘられる。

\section{II. 試 結 果}

(1) 鐸物砂の耐火度に及ぼす $\mathrm{Al}_{2} \mathbf{O}_{3}$ 及で $\mathrm{Fe}_{2} \mathbf{O}_{3}$ の影響
䥂物仯の不純物としては $\mathrm{Al}_{2} \mathrm{O}_{3}$ 皮で $\mathrm{Fe}_{2} \mathrm{O}_{3}$ が代表的でをる

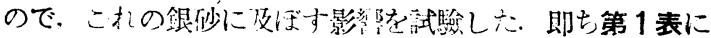

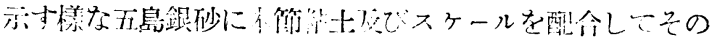
第 1 㤗 开皇勧仯成分表

\begin{tabular}{|c|c|c|c|c|c|c|}
\hline 成 分 & $\mathrm{SiO}_{2}$ & \multicolumn{2}{|c|}{$\mathrm{Fe}_{2} \mathrm{O}_{3}+\mathrm{Al}_{2} \mathrm{O}_{3}$} & $\mathrm{TiO}_{2}$ & $\mathrm{CaO}$ & 枃䰻娍量 \\
\hline$(0,0)$ & 93.22 & 0.49 & 3.62 & tr. & 0.80 & 1.29 \\
\hline 成 分 & $\mathrm{MgO}$ & $\mathrm{Ma}_{2} \mathrm{O}$ & $\mathrm{K}_{2} \mathrm{O}$ & 水分 & - & 苝悠娍琶 \\
\hline$(0)$ & 0.57 & 0.40 & tr. & 0.24 & - & 1.29 \\
\hline
\end{tabular}

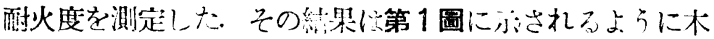

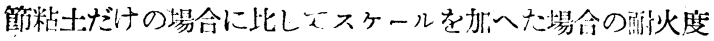

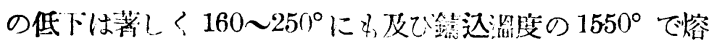

